Article

\title{
Facile Synthesis and Preferred Conformation Analysis of Cyclododeceno[b]indene
}

\author{
Chunyan Zhang, Shengyan Gong, Li Zhang, Daoquan Wang and Mingan Wang * \\ Department of Applied Chemistry, China Agricultural University, Beijing 100193, China \\ * Author to whom correspondence should be addressed; E-Mail: wangma@cau.edu.cn; \\ Tel.: +86-10-62734093.
}

Received: 23 December 2009; in revised form: 21 January 2010 / Accepted: 25 January 2010 /

Published: 1 February 2010

\begin{abstract}
Using methanesulfonic acid as a catalyst, a series of cyclododeceno[b]indene derivatives were synthesized by the cyclization of $\alpha$-benzylcyclododecanones, which were prepared by the reactions of cyclododecanones with a variety of substituted benzyl chlorides or bromides using $\mathrm{NaH}$ as a base. Their structures were confirmed by mp, IR spectra, ${ }^{1} \mathrm{H}-\mathrm{NMR},{ }^{13} \mathrm{C}-\mathrm{NMR}, \mathrm{MS}$, and $\mathrm{x}$-ray diffraction. The preferred conformations were analyzed by crystal structure, ${ }^{1} \mathrm{H}-\mathrm{NMR}$ and quantum chemistry calculations, and compared with the x-ray diffraction structure of 2,3,5,6-bis(ortho-1,10-decylidene)dihydropyrazine. The results showed that the cyclododecene moiety adopted a preferred [1ene2333] conformation, and the substituted groups at aromatic ring had no significant influence on the conformation.
\end{abstract}

Keywords: $\alpha$-benzylcyclododecanone; cyclododeceno[b]indene; synthesis; conformational analysis

\section{Introduction}

Benzocyclopenta-1,3-diene (indene) is a compound with an $8 \pi$-electron system in a planar conformation that makes it easy to lose one proton and form a $10 \pi$-electron aromatic system, and therefore plays an important role in Organic Chemistry. Indene derivatives are widely used as useful intermediates in the development of drug molecules, pesticides, and functional materials [1,2]. They have also been used as metal ligands of Ziegler-Natta type catalysts, and these complexes are highly 
stable and have excellent catalytic efficacy in the polymerization of ethylene and propylene $[3,4]$. Cyclohexeno[b]indene in particular has been used as a Ziegler-Natta catalyst metal ligand [5]. In another aspect, bi- and tricyclic compounds with bridge double bonds are very useful starting reagents for the synthesis of macrocyclic compounds such as the fragrant macrocyclic lactone pentadecanolide and related compounds [6,7]. Synthesis of indene derivatives containing cyclic olefins ranging from 5 to 12-membered rings have been reported, with the exception of the corresponding 11-membered ring compounds. As for cyclododeceno[b]indene, it has been reported by Parham and coworkers [8] that this compound can be synthesized in five steps using cyclododecanone and a Grignard reagent as starting materials. However the reaction conditions are difficult to control, the intermediates are hard to purify, and the overall yield is low. Zakharkin and coworkers [9] reported a convenient method in which $\alpha$-benzylcyclododecanones were synthesized by the reaction of cyclododecanone with benzyl chloride under phase transfer catalysis, followed by cyclization of $\alpha$-benzylcyclododecanone using polyphosphoric acid as the catalyst. Recently, Miyamoto and coworker [10] reported a Rh(I)-catalyzed reaction of 2-(chloromethyl)phenylboronic acid and cyclododecyne leading to cyclododeceno[b]indene in $36 \%-54 \%$ yields, but cyclododecyne is not readily available.

So far, cyclododeceno[b]indene derivatives have not been evaluated for their catalytic efficacy as metal ligands of Ziegler-Natta type catalysts. Moreover, it is not clear whether the conformation of the cyclododecene ring in cyclododeceno[b]indene molecules has any significant impact on the catalytic efficacy of these compounds. In order to resolve these issues and extend our research on the stereochemistry of 12-membered ring systems [11-15], we have synthesized a series of cyclododeceno[b]indene derivatives using methanesulfonic acid as catalyst and carried out the conformational analysis of these compounds. The synthetic route is shown in Scheme 1. The evaluation of the catalytic efficacy of these compounds are still in progress in our laboratory.

Scheme 1. The synthetic route of cyclododeceno[b]indene derivatives.

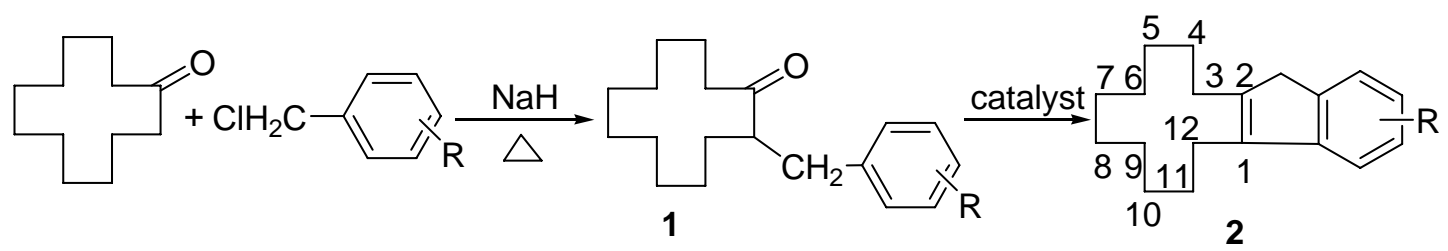

A. $\mathrm{R}=\mathrm{H}$ B. $\mathrm{R}=4-\mathrm{Cl}$ C. $\mathrm{R}=4-\mathrm{F}$ D. $\mathrm{R}=4-\mathrm{CH}_{3}$ E. $\mathrm{R}=4-\mathrm{OCH}_{3} \quad$ F. $\mathrm{R}=2,4-\mathrm{Cl}_{2}$

\section{Results and Discussion}

In the synthesis of the title compounds, we found that the cyclization of intermediates $\mathbf{1}$ did not take place after several days using the Zakharkin method when $n$-hexane was used as solvent and PPA or phosphoric acid as the catalysts [9]. We next used the more acidic $p$-methylbenzenesulfonic acid as the catalyst, which enabled the reaction of $\alpha$-benzylcyclododecanone $(\mathbf{1 A})$ to produce compound $2 \mathbf{A}$ in $30 \%$ yield, but para-fluoro- or para-chloro- $\alpha$-benzylcyclododecanones $\mathbf{1 B}$ and $\mathbf{1 C}$ did not react under similar conditions. This may be due to the heterogenous nature of these reactions because $p$-methylbenzenesulfonic acid remained in a solid state in the reaction mixtures, which resulted in poor catalytic efficacy of the reagent. Then we used anhydrous aluminum chloride as the catalyst as in [5], where Thomas reported the synthesis of cyclohexeno[b]indene by the cyclization reaction of $\alpha$-benzylcyclo- 
hexanone in the presence of anhydrous aluminum chloride. The results showed that in hexane the products were complex and difficult to purify when 1A-4A were used as the starting materials. Considering the characteristics of the dehydration after the electrophilic cyclization, as indicated in Scheme 2, we tried methanesulfonic acid as the catalyst in an amount that was 2-3 times the amount of $\alpha$-benzylcyclododecanone used. As a result, we found that the reaction time was shortened, the products were relatively easier to isolate, and the yields were in the 5-16\% range for 2A, 2C, 2D and 2E. Compound 2B was an exception. Encouraged by these results, we added a 10-fold excess of methanesulfonic acid without changing the other conditions, and were able to achieve yields of 3590\% for 2A, 2B, 2C, 2D and 2E, respectively. Compound 1F still did not afford 2F. Comparing these results with the reaction yields and conditions used for $\alpha$-benzylcyclohexanone [5], we found that it is more difficult to obtain the cyclization products of $\alpha$-benzylcyclododecanone, which may be attributed to the conformational difference between the six-membered and twelve-membered ring ketones involved [16].

Scheme 2. The cyclization mechanism of the title compounds.

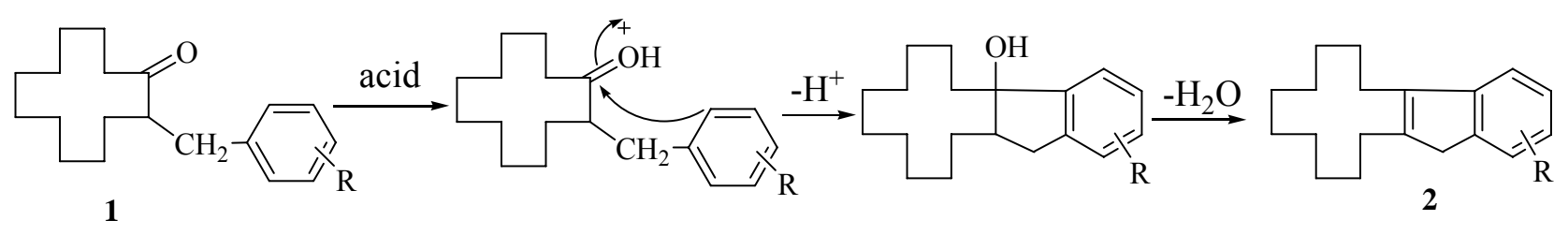

The preferred conformation of cis-cyclododecene and its derivatives is [1ene2333], as discussed by several research groups [17-20], but research on the preferred conformation of trans-cyclododecene is rather minimal [21] and a fundamental conclusion has not yet been reached. The title compounds 2B-2D are colorless crystals, but our attempts at growing a suitable single crystal in $n$-hexane and cyclohexane were not successful, while 2 A was successfully crystallized from $n$-hexane and subjected to $\mathrm{x}$-ray diffraction analysis. The results (Figure 1) show that a cis-configuration and the preferred [1ene2333] conformation for the cis-cyclododecene moiety are present in the crystals of $\mathbf{2 A}$, and the benzocyclopenta-1,3-diene moiety adopts a planar structure. The preferred [1ene2333] conformation of the cis-cyclododecene moiety was consistent with that seen in the crystals of other similar molecules like 15-phenylbicyclo-[10,3,0]pentadec-1(12)-en-13-one [19], 1-methoxycarbonyloxyl-2phenoxy- carbonyl-1,2-cyclododecene, 1-phenoxycarbonyloxyl-2-methoxycarbonyl-1,2cyclododecene [11], and 2,3,5,6-bis(ortho-1,10-decylidene)dihydropyrazine [15].

In the [1ene2333] conformation, the two protons of the 3- $\mathrm{CH}_{2}$ and $12-\mathrm{CH}_{2}$ occupy side-exo and side-endo-positions, respectively, and therefore they should display different chemical shifts in the ${ }^{1} \mathrm{H}$ NMR spectrum. However, in the ${ }^{1} \mathrm{H}-\mathrm{NMR}$ spectra of $\mathbf{2 A - 2 E}$, the two protons on each side of the asymmetric 1,2-disubstituted cyclododecene appeared as equivalent protons which are coupled with their adjacent protons to give triplet signals with $7.0 \mathrm{~Hz}$ coupling constants. These results are consistent with the ${ }^{1} \mathrm{H}-\mathrm{NMR}$ characteristics of asymmetric 1,2-disubstituted cyclododecene reported in our previous paper [11,15], and show that 2 may adopt two different [1 ene2333] conformations like other asymmetric 1,2-disubstituted cyclododecenes, which coexist in a dynamic equilibrium in 
solution $[11,19,20]$. The ${ }^{1} \mathrm{H}-\mathrm{NMR}$ spectra in solution are the averaged results of these two different [1ene2333] conformations. Compound 2A adopted one of the two conformations in its crystal form.

Figure 1. The crystal structure of compound 2A.
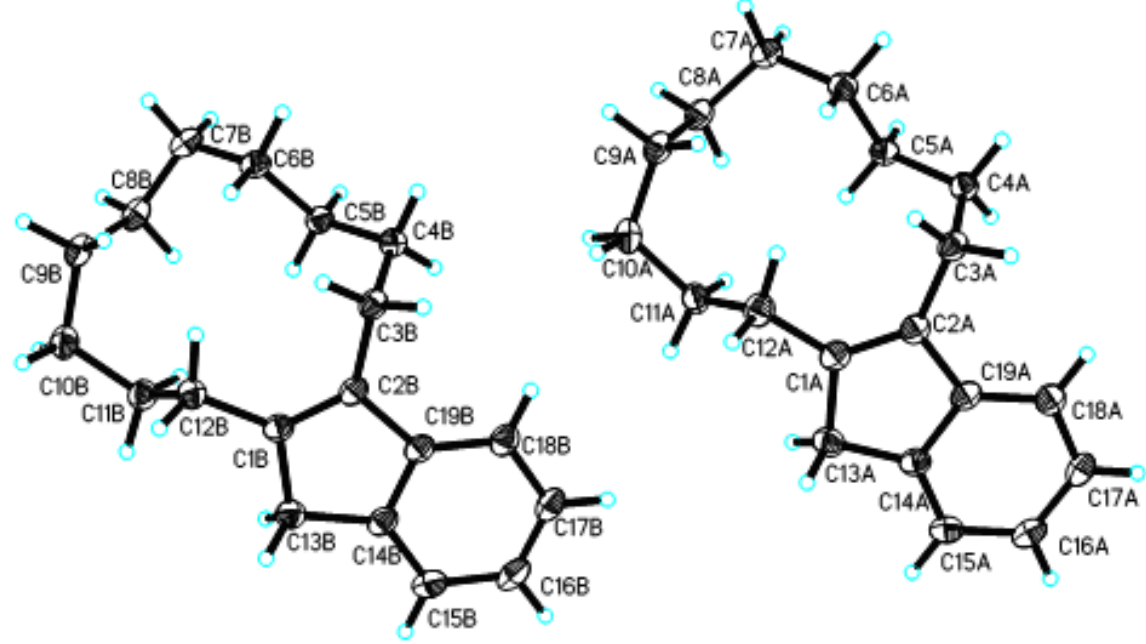

In order to validate our conclusions, the quantum chemistry method was used to analyze the conformation of the title compounds. The conformational optimization was performed for $\mathbf{2 A - 2 E}$ using the Gaussian 03 software and the results compared with the x-ray diffraction structures of 2A and 2,3,5,6-bis( ortho-1,10-decylidene)dihydropyrazine [15]. Vibrational frequencies were computed at the same level, and the positive values of the first frequency for the title compounds showed the optimized conformations were the local energy minimum conformations and located the stationary points. Using 2A as example, its optimized structure was completely consistent with the obtained x-ray structure and it also showed the same [1ene2333] conformation of 2,3,5,6-bis( ortho-1,10decylidene)dihydro-pyrazine, as seen in the superimposed diagrams in Figure 2(A). Similarly, we analyzed the optimized structures of $\mathbf{2 B}-\mathbf{2 E}$ and superimposed them with that of $\mathbf{2 A}$ as seen in Figure 2(B). They all matched pretty well, and the conformational differences between the cis-cyclododecene and the benzocyclopenta-1,3-diene moieties were insignificant. These results implied that the cyclododecene moiety in the optimized structures of 2A-2E adopts a [1ene2333] conformation, and the indene ring and its substituents have no significant influence on the conformation of the cyclododecene moiety.

We also compared the torsion angles of $2 \mathbf{A}-2 \mathbf{E}$ (Table 1), and found that the changes of all twelve torsion angles of $\mathbf{2 A}-\mathbf{2 E}$ are in the range of $0-1^{\circ}$, indicating that the structural differences between the five compounds are minimal. Further, we compared the torsion angles of $\mathbf{2 A - 2 E}$ with those of 2,3,5,6bis(ortho-1,10-decylidene)dihydropyrazine, the changes of all twelve torsion angels are in the range of 0-9.1 ${ }^{\circ}$, especially the angels $\mathrm{C} 1-\mathrm{C} 2-\mathrm{C} 3-\mathrm{C} 4, \mathrm{C} 2-\mathrm{C} 3-\mathrm{C} 4-\mathrm{C} 5$ and $\mathrm{C} 3-\mathrm{C} 4-\mathrm{C} 5-\mathrm{C} 6$ are 9.1, 6.7 and 3.8, respectively. This may be due to the various influences of different rings connecting cyclododecene and the relative distances near the double bond of cyclododecene. The larger the relative distance is, the smaller the torsion angel changes. The other torsion angels showed only 0-3 ${ }^{\circ}$ difference. Again, this comparison indicated that the cis-cyclododecene moiety in $\mathbf{2 A - 2 E}$ and 2,3,5,6-bis (ortho-1, 10decylidene) dihydropyrazine take the same [1ene2333] preferred conformation. 
Figure 2. Superimposed diagrams of $\mathbf{2 A - 2 E}$ and 2,3,5,6-bis(ortho-1,10-decylidene)dihydropyrazine.

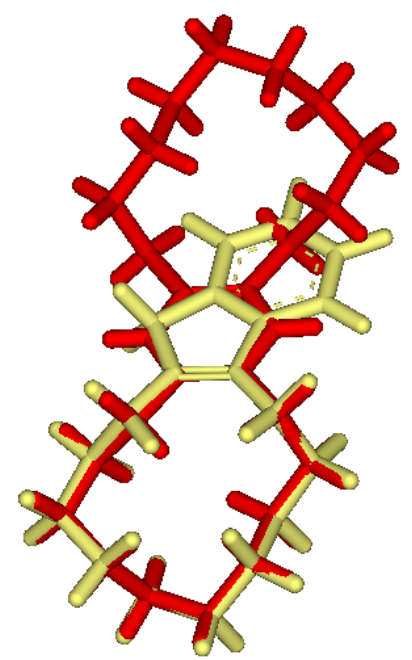

A

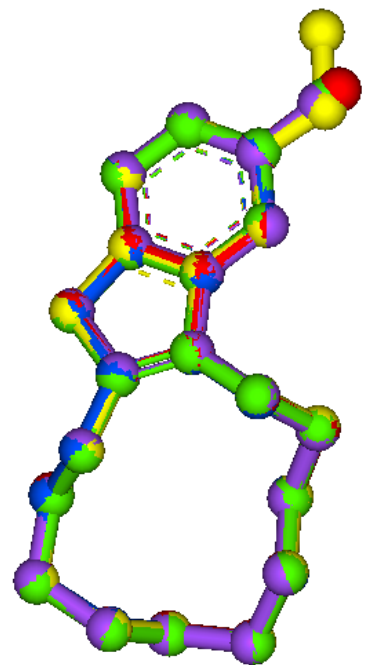

B

\section{A: blue 2B: Green 2C: orange 2D: purple 2E: red}

Table 1. The torsion angles of 2A-2E and 2,3,5,6-bis( ortho-1,10-decylidene)dihydropyrazine.

\begin{tabular}{|c|c|c|c|c|c|c|}
\hline \multirow{2}{*}{ Angle } & \multicolumn{6}{|c|}{ Torsion angle $\left({ }^{\circ}\right)$} \\
\hline & $2 A$ & 2B & $2 C$ & $2 D$ & $2 E$ & Ref. [13] \\
\hline $\mathrm{C} 1-\mathrm{C} 2-\mathrm{C} 3-\mathrm{C} 4$ & $-117.0\left(-118.1^{\mathrm{a}}\right)$ & -117.0 & -117.1 & -117.0 & -117.2 & -126.1 \\
\hline $\mathrm{C} 2-\mathrm{C} 3-\mathrm{C} 4-\mathrm{C} 5$ & $162.0(166.6)$ & 162.7 & 162.5 & 162.8 & 162.6 & 168.7 \\
\hline C3-C4-C5-C6 & $-65.2(-65.0)$ & -65.0 & -64.9 & -65.0 & -64.8 & -61.4 \\
\hline $\mathrm{C} 4-\mathrm{C} 5-\mathrm{C} 6-\mathrm{C} 7$ & $-64.5(-64.5)$ & -64.2 & -64.3 & -64.2 & -64.2 & -63.3 \\
\hline $\mathrm{C} 5-\mathrm{C} 6-\mathrm{C} 7-\mathrm{C} 8$ & $150.8(147.2)$ & 150.1 & 150.3 & 150.0 & 150.2 & 148.9 \\
\hline C6-C7-C8-C9 & $-65.1(-64.6)$ & -65.3 & -65.3 & -65.3 & -65.3 & -65.1 \\
\hline $\mathrm{C} 7-\mathrm{C} 8-\mathrm{C} 9-\mathrm{C} 10$ & $-62.7(-62.2)$ & -63.1 & -63.3 & -63.0 & -63.4 & -61.5 \\
\hline C8-C9-C10-C11 & $175.6(178.9)$ & 176.0 & 175.7 & 176.1 & 175.8 & 177.8 \\
\hline C9-C10-C11-C12 & $-74.3(-73.1)$ & -73.7 & -73.4 & -73.7 & -73.3 & -76.3 \\
\hline C10-C11-C12-C1 & $-73.0(-71.2)$ & -73.0 & -73.1 & -72.9 & -73.0 & -74.2 \\
\hline $\mathrm{C} 11-\mathrm{C} 12-\mathrm{C} 1-\mathrm{C} 2$ & $105.4(100.8)$ & 105.0 & 105.4 & 104.8 & 105.2 & 102.4 \\
\hline $\mathrm{C} 12-\mathrm{C} 1-\mathrm{C} 2-\mathrm{C} 3$ & $-1.5(-2.4)$ & -1.8 & -1.8 & -1.7 & -1.8 & -0.6 \\
\hline
\end{tabular}

${ }^{\text {a }}$ These data are from the $\mathrm{x}$-ray diffraction crystal structure of $\mathbf{2 A}$.

Thomas [5] found that metallocenes containing indene were highly stable and efficient ZieglerNatta type catalysts for the polymerization of ethylene and propylene, but that lower polymer molecular weights were obtained with the systems, which were attributed to the more indenyl-like character of the systems or to the less rigid geometry of cyclohexene ring in the complexes. Based on this observation, the relatively rigid [1ene2333] conformation of the cyclododecene ring in the cyclododeceno[b]indene derivatives may be helpful to improve polymer molecular weights in the polymerization of ethylene and propylene when using cyclododeceno[b]indene derivatives as ZieglerNatta type catalyst ligands. This is the subject of further studies being performed by our group. 


\section{Experimental}

\subsection{General}

Melting points were measured on a Yanagimoto NFG CO apparatus and are uncorrected; IR spectra were determined on an IR-450 instrument; ${ }^{1} \mathrm{H}-\mathrm{NMR}$ and ${ }^{13} \mathrm{C}-\mathrm{NMR}$ spectra were recorded on a Brüker DPX 300 NMR spectrometer with $\mathrm{CDCl}_{3}$ as solvent and TMS as internal standard. APCI-MS was recorded with an Agilent LCQ LC-MSD ion-trap mass spectrometer. Cyclododecanone (99.8\%) was purchased from Acros Organics; $p$-chlorobenzyl chloride (99\%) and $p$-fluorobenzyl chloride (99\%) were from Johnson Matthey; $p$-methylbenzyl chloride (99\%) was from Alfa Aesar; $o, p$ dichlorobenzyl chloride (98\%) was from Avocado; $p$-methoxybenzyl alcohol (98\%) was from Merck; $\mathrm{NaH}(80 \%)$ was from Beijing Chemical Reagent Co.; PPA $\left(80 \%, \mathrm{P}_{2} \mathrm{O}_{5}\right)$, anhydrous aluminum chloride (99\%) and methanesulfonic acid (98.5-101\%) were from Beijing Yili Chemicals Co.; $p$-methylbenzenesulfonic acid (98\%) was from Shanghai Reagent factory; the solvents were analytical grade and treated with sodium and benzophenone before usage.

\subsection{Crystallographic Data}

CCDC 759652 contains the supplementary crystallographic data for this paper. These data can be obtained free of charge via www.ccdc.cam.ac.ck/conts/retrieving.html (or from CCDC, 12 Union Road, Cambridge CB2 1EZ, UK. Fax: +44 1223 336033; E-Mail: deposit@ccdc.cam.ac.uk).

\subsection{General Synthetic Method for Intermediates $\mathbf{1 A - 1 F}$}

Compounds 1A-1F were synthesized in $57-80 \%$ yields according to the procedure reported in $[12,22]$. Among them, $p$-methoxybenzyl bromide was prepared using $p$-methoxybenzyl alcohol and hydrogen bromide [23], and utilized in the next reaction without further purification. The mp, IR, ${ }^{1} \mathrm{H}$ - and ${ }^{13} \mathrm{C}-\mathrm{NMR}$ of $\mathbf{1 A}$ were consistent with the data in the literature [12].

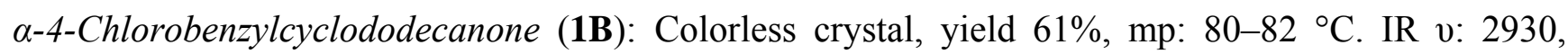
$1710,1590,1490,1430,1400,1355,1105,1020,1000,855,810,720,700 \mathrm{~cm}^{-1} .{ }^{1} \mathrm{H}-\mathrm{NMR} \delta: 7.20-7.26$ $(\mathrm{m}, 2 \mathrm{H}), 7.06-7.10(\mathrm{~m}, 2 \mathrm{H}), 2.85-2.94(\mathrm{~m}, 2 \mathrm{H}), 2.49-2.62(\mathrm{~m}, 2 \mathrm{H}), 2.16-2.25(\mathrm{~m}, 1 \mathrm{H}), 1.54-1.76(\mathrm{~m}$, $4 \mathrm{H}), 1.29-1.25(\mathrm{~m}, 14 \mathrm{H}) .{ }^{13} \mathrm{C}-\mathrm{NMR} \delta: 213.62,138.41,131.91,130.16,128.48,53.19,38.46,36.50$, $29.31,26.09,25.76,23.84,23.67,22.33,22.24,21.83$.

$\alpha$-4-Flurobenzylcyclododecanone (1C): Colorless crystal, yield 60\%, mp: $68-69^{\circ} \mathrm{C}$. IR v: 2920, 1715 , 1595, 1490, 1435, 1400, 1355, 1105, 1020, 1000, 850, 810, 720, $705 \mathrm{~cm}^{-1} .{ }^{1} \mathrm{H}-\mathrm{NMR}$ 8: 7.07-7.13 (m, $2 \mathrm{H}), 6.91-6.98(\mathrm{~m}, 2 \mathrm{H}), 2.85-2.92(\mathrm{~m}, 2 \mathrm{H}), 2.47-2.65(\mathrm{~m}, 2 \mathrm{H}), 2.16-2.26(\mathrm{~m}, 1 \mathrm{H}), 1.54-1.75(\mathrm{~m}, 4 \mathrm{H})$, $1.29-1.26(\mathrm{~m}, 14 \mathrm{H}) .{ }^{13} \mathrm{C}-\mathrm{NMR} \delta: 213.88,161.39\left({ }^{1} J_{\mathrm{FC}}=240.0 \mathrm{~Hz}\right), 135.53\left({ }^{4} J_{\mathrm{FC}}=3.1 \mathrm{~Hz}\right), 130.19$ $\left({ }^{3} J_{\mathrm{FC}}=7.8 \mathrm{~Hz}\right), 115.13\left({ }^{2} J_{\mathrm{FC}}=21.1 \mathrm{~Hz}\right), 53.38,38.52,36.47,29.35,25.73,24.10,23.90,23.75,22.43$, $22.24,21.85$.

a-4-Methylbenzylcyclododecanone (1D): Colorless crystal, yield 57\%, mp: $68-70{ }^{\circ} \mathrm{C}$. IR v: 2925 , 1718, 1605, 1495, 1430, 1405, 1360, 1100, 1020, 1010, 855, 805, $720 \mathrm{~cm}^{-1} .{ }^{1} \mathrm{H}-\mathrm{NMR}$ 8: 7.09-7.02 (m, 
4H), 2.94-2.83 (m, 2H), 2.63-2.44 (m, 2H), 2.30-2.22 (m, 4H), 1.71-1.57 (m, 4H), 1.28-1.27 (m, 14H).

${ }^{13} \mathrm{C}-\mathrm{NMR} \delta$ : 214.35, 136.74, 135.62, 129.08, 128.71, 53.39, 38.51, 37.18, 29.44, 25.74, 24.20, 24.07, 23.96, 22.72, 22.33, 21.95, 20.98 .

a-4-Methoxybenzylcyclododecanone (1E): Colorless crystal, yield $78 \%$, mp: $75-76{ }^{\circ} \mathrm{C}$. IR v: 2920 , 1700, 1590, 1500, 1450, 1430, 1250, 1170, 1100, 1050, 950, 800, 720, $690 \mathrm{~cm}^{-1} .{ }^{1} \mathrm{H}-\mathrm{NMR} \delta: 7.09-7.04$ $(\mathrm{m}, 2 \mathrm{H}), 6.83-6.78(\mathrm{~m}, 2 \mathrm{H}), 3.78(\mathrm{~s}, 3 \mathrm{H}), 2.91-2.80(\mathrm{~m}, 2 \mathrm{H}), 2.62-2.57(\mathrm{~m}, 1 \mathrm{H}), 2.52-2.42(\mathrm{~m}, 1 \mathrm{H})$, 2.29-2.19 (m, 1H), 1.71-1.28 (m, 4H), 1.27(m, 14H). ${ }^{13} \mathrm{C}-\mathrm{NMR} \delta: 214.47,158.00,131.86,129.74$, $113.82,55.20,53.50,38.60,36.78,29.45,26.10,25.69,24.18,24.06,23.96,22.71,22.29,21.94$.

$\alpha$-2,4-Dichlorobenzylcyclododecanone (1F): Colorless crystal, yield 76\%, mp: $94-95{ }^{\circ} \mathrm{C}$. IR v: 2920 , $1700,1590,1470,1430,1400,1350,1100,1020,1000,850,800,720,700 \mathrm{~cm}^{-1} .{ }^{1} \mathrm{H}-\mathrm{NMR} \delta: 7.36-7.33$ (m, 1H), 7.17-6.94 (m, 2H), 3.12-2.99 (m, 2H), 2.72-2.60 (m, 2H), 2.20-2.10 (m, 1H), 1.81-1.53 (m, 2H), 1.29-1.22 (m, 16H). ${ }^{13} \mathrm{C}-\mathrm{NMR} \delta: 213.48,136.31,132.69,132.44,129.35,126.98,126.88,50.44$, $38.96,34.32,29.40,26.01,25.62,24.16,24.01,23.86,22.35,22.33,21.94$.

\subsection{General Synthetic Method for the Title Compounds $\mathbf{2 A - 2 E}$}

Taking 2D as an example: anhydrous $n$-hexane $(30 \mathrm{~mL})$ and $1.3 \mathrm{~mL}(0.02 \mathrm{~mol})$ methylsulfonic acid were added to a $100 \mathrm{~mL}$ three-necked bottle, then $0.6 \mathrm{~g}$ (0.002 mol) $\alpha$-(4-methylbenzyl) cyclododecanone was added into the bottle under stirring and heated to keep reflux. After the reaction was completed (three days after TLC check), water $(30 \mathrm{~mL})$ was added to the mixture. The mixture was extracted three times with n-hexane $(3 \times 30 \mathrm{~mL})$, and the combined organic layer was washed with saturated $\mathrm{NaCl}$ solution, dried with anhydrous $\mathrm{MgSO}_{4}$, filtered and evaporated under reduced pressure to give an pale yellow oil. The oil was chromatographed on a silica gel column and washed with redistilled petroleum ether. 0.5 g colorless crystal was afforded in $90 \%$ yield. Similarly, 2A-2E was synthesized successfully, but $\mathbf{2 F}$ was an exception.

Cyclododeceno[b] indene (2A): Colorless crystals, mp 53-55 ${ }^{\circ} \mathrm{C}, 50 \%$ yield. IR v: $2950,1620,1595$, 1490, 1435, 1400, 1350, $1105 \mathrm{~cm}^{-1} .{ }^{1} \mathrm{H}-\mathrm{NMR}$ 8: 7.39-7.08 (m, 4H), $3.28(\mathrm{~s}, 2 \mathrm{H}), 2.58$ (t, J=7.0 Hz, 2H), $2.47(\mathrm{t}, J=7.2 \mathrm{~Hz}, 2 \mathrm{H}), 1.76-1.65(\mathrm{~m}, 4 \mathrm{H}), 1.52-1.24(\mathrm{~m}, 12 \mathrm{H}) .{ }^{13} \mathrm{C}-\mathrm{NMR} \delta: 146.73,143.79$, $142.87,136.93,125.92,123.47,123.21,118.85,39.96,27.17,26.04,25.30,25.15,25.08,24.92,23.69$, 22.80, 22.33, 22.00. NMR data were consistent with the data in the literature $[6,8]$. APCI-MS: 255 $[\mathrm{M}+\mathrm{H}]^{+}$.

3-Chlorocyclododeceno[b]indene (2B): Colorless crystals, $\mathrm{mp} 78-80{ }^{\circ} \mathrm{C}, 35 \%$ yield. IR v: 2960, 1625, 1590, 1495, 1430, 1405, 1350, $1110 \mathrm{~cm}^{-1} .{ }^{1} \mathrm{H}-\mathrm{NMR} \delta: 7.27-7.23(\mathrm{~m}, 2 \mathrm{H}), 7.08-7.05(\mathrm{dd}, J=7.8$, $2.0 \mathrm{~Hz}, 1 \mathrm{H}), 3.25(\mathrm{~s}, 2 \mathrm{H}), 2.52(\mathrm{t}, J=7.0 \mathrm{~Hz}, 2 \mathrm{H}), 2.47$ (t, $J=7.2 \mathrm{~Hz} 2 \mathrm{H}), 1.74-1.64(\mathrm{~m}, 4 \mathrm{H}), 1.50-$ $1.22(\mathrm{~m}, 12 \mathrm{H}) .{ }^{13} \mathrm{C}-\mathrm{NMR} \delta: 148.61,145.88,141.03,136.57,132.06,123.99,123.29,119.11,39.59$, $27.14,25.95,25.42,25.14,25.12,24.94,23.75,22.79,22.28,22.05$. APCI-MS: $289[\mathrm{M}+\mathrm{H}]^{+}$.

3-Flurocyclododeceno[b] indene (2C): Colorless crystals, mp 50-52 ${ }^{\circ} \mathrm{C}, 46 \%$ yield. IR v: 2955,1620 , 1590, 1495, 1440, 1410, 1355, $1105 \mathrm{~cm}^{-1} .{ }^{1} \mathrm{H}-\mathrm{NMR} \delta$ : 7.28-7.24 (m, 1H), 6.98-6.94 (m, 1H), 6.81-6.75 (m, 1H), 3.24 (s, 2H), 2.54 (t, $J=7.0 \mathrm{~Hz}, 2 \mathrm{H}), 2.47$ (t, $J=7.2 \mathrm{~Hz}, 2 \mathrm{H}), 1.74-1.64(\mathrm{~m}, 4 \mathrm{H}), 1.51-1.23$ 
$(\mathrm{m}, 12 \mathrm{H}) .{ }^{13} \mathrm{C}-\mathrm{NMR} \delta: 162.45\left({ }^{1} \mathrm{~J}_{\mathrm{FC}}=240.9 \mathrm{~Hz}\right), 148.75\left({ }^{3} \mathrm{~J}_{\mathrm{FC}}=8.4 \mathrm{~Hz}\right), 146.38,137.95\left({ }^{4} \mathrm{~J}_{\mathrm{FH}}=2.5\right.$ $\mathrm{Hz}), 136.73\left({ }^{4} \mathrm{~J}_{\mathrm{FH}}=2.9 \mathrm{~Hz}\right), 123.66\left({ }^{3} \mathrm{~J}_{\mathrm{FH}}=9.1 \mathrm{~Hz}\right), 109.83\left({ }^{2} J_{\mathrm{FH}}=22.9 \mathrm{~Hz}\right), 106.05\left({ }^{2} J_{\mathrm{FH}}=22.9 \mathrm{~Hz}\right)$, $39.37,27.14,25.91,25.46,25.14,25.10,24.91,23.72,22.78,22.31,22.02$. APCI-MS: 273 [M+H] ${ }^{+}$.

3-Methylcyclododeceno[b] indene (2D): Colorless crystals, mp 50-52 ${ }^{\circ} \mathrm{C}, 90 \%$ yield. IR v: 2950, 1624, 1595, 1490, 1445, 1405, 1350, $1110 \mathrm{~cm}^{-1} .{ }^{1} \mathrm{H}-\mathrm{NMR} \delta: 7.25(\mathrm{~d}, J=7.5 \mathrm{~Hz}, 1 \mathrm{H}), 7.10(\mathrm{~d}, J=1.5 \mathrm{~Hz}$, 1H), $6.92(\mathrm{dd}, J=7.51 .5 \mathrm{~Hz}, 1 \mathrm{H}), 3.24(\mathrm{~s}, 2 \mathrm{H}), 2.56(\mathrm{t}, J=6.9 \mathrm{~Hz}, 2 \mathrm{H}), 2.46(\mathrm{t}, J=7.2 \mathrm{~Hz} 2 \mathrm{H})$, 2.39(s, 3H), 1.76-1.63 (m, 4H), 1.51-1.24(m, 12H). ${ }^{13} \mathrm{C}-\mathrm{NMR} \delta: 146.99,144.08,139.92,136.85$, 135.44, 124.24, 122.89, 119.67, 39.58, 27.21, 26.10, 25.38, 25.19, 25.12, 25.00, 23.78, 22.85, 22.37, 22.06, 21.58. APCI-MS: $269[\mathrm{M}+\mathrm{H}]^{+}$.

3-Methoxycyclododeceno[b] indene (2E): Light yellow oil, 62\% yield. IR v: 2960, 1625, 1592, 1495, 1450, 1415, 1340, $1115 \mathrm{~cm}^{-1} .{ }^{1} \mathrm{H}-\mathrm{NMR} \delta: 7.26(\mathrm{~d}, J=7.8 \mathrm{~Hz}, 1 \mathrm{H}), 6.85(\mathrm{~d}, J=2.4 \mathrm{~Hz}, 1 \mathrm{H}), 6.66(\mathrm{dd}$, $J=7.8,2.4 \mathrm{~Hz}, 1 \mathrm{H}), 3.83(\mathrm{~s}, 3 \mathrm{H}), 3.23(\mathrm{~s}, 2 \mathrm{H}), 2.56(\mathrm{t}, J=6.9 \mathrm{~Hz}, 2 \mathrm{H}), 2.46(\mathrm{t}, J=7.2 \mathrm{~Hz} 2 \mathrm{H}), 1.73-$ $1.44(\mathrm{~m}, 4 \mathrm{H}), 1.39-1.24(\mathrm{~m}, 12 \mathrm{H}) .{ }^{13} \mathrm{C}-\mathrm{NMR} \delta: 158.85,148.25,145.47,136.83,135.02,123.44$, 108.77, 105.34, 55.55, 39.22, 27.17, 26.04, 25.47, 25.18, 25.13, 24.96, 23.73, 22.84, 22.34, 22.04. APCI-MS: $285[\mathrm{M}+\mathrm{H}]^{+}$.

\subsection{X-Ray Diffraction of Compound 2A}

The crystal of compound 2A was obtained by slow evaporation of a hexane solution. X-ray diffraction analysis: all measurements for $0.50 \times 0.49 \times 0.45 \mathrm{~mm}$ crystal were made with a Rigaku Raxis RAPID IP four circle area detector using graphite monochromatized Mo $\operatorname{Ka}(\lambda=0.071073 \mathrm{~nm})$ radiation at $73 \mathrm{~K}$. Full spheres of data were collected to a $2 \theta$ limit of $25.00^{\circ} .19888$ reflections were collected with 5233 unique [R(int) $=0.0366], 4929$ reflections were stronger than $2 \sigma$ in intensity. Space groups were determined from systematic absence and checked for higher symmetry. The structures were solved by direct methods using SHELX, and refined on $F^{2}$ using all data by full-matrix least-squares procedures with SHELXL-97. All non-hydrogen atoms were refined with anisotropic displacement parameters. An empirical absorption correction based on Xscans was made on all data. Hydrogen atoms were located from the difference map and were constrained to geometrical estimates. Final refinement was carried out with isotropic displacement parameters applied to hydrogen atoms. The crystal structure parameters for $2 \mathrm{~A}$ was: $\mathrm{C}_{19} \mathrm{H}_{26}, \quad M_{r}=254.40$, monoclinic, space group P2(1)/c, $a=1.4406(3), b=1.6472(3), c=1.2580(3) \mathrm{nm}, \beta=93.36(3)^{\circ}, V=2.9799(10) \mathrm{nm}^{3}, D c=1.134 \mathrm{~g} / \mathrm{cm}^{3}$, $Z=8, F(000)=1120, \mu($ Mo $K \alpha)=0.063 \mathrm{~mm}^{-1}$, final $R=0.0653, w R=0.1725$.

\subsection{Conformational Optimization of Compounds 2A-2E}

The geometry optimizations were performed by the DFT method using the B3LYP functional $[24,25]$. A standard valence double-zeta with polarization function 6-31G $(d, p)$ basis set [26] was used for all kinds of atoms involved in five target molecules (2A-2E). Vibration frequencies were computed at the B3LYP/6-31G $(d, p)$ levels to characterize stationary points. All calculations were performed using the Gaussian 03 software [27]. 


\section{Conclusions}

Five cyclododeceno[b]indene derivatives were easily prepared in good yields using $\alpha$-benzylcyclododecanone as the raw material, and a 10-fold excess of methanesulfonic acid as catalyst. The preferred conformations were analysized by x-ray diffraction, ${ }^{1} \mathrm{H}-\mathrm{NMR}$ and quantum chemistry calculations, and compared with the X-ray diffraction structure of 2,3,5,6-bis(ortho-1,10-decylidene)dihydropyrazine. The results have shown that the cis-cyclododecene moiety in the title compounds adopts a preferred [1ene2333] conformation, and that while two asymmetric [1 ene2333] conformations coexist in a dynamic equilibrium in solution, only one [1ene2333] conformation is present in the crystal solid, and the substituted groups at aromatic ring do not have significant influence on the conformation of the cyclododecene moiety.

\section{Acknowledgements}

The authors are grateful to the National Natural Science Foundation of China (Nos. 20772150, 20072053) and the Foundation of China Agricultural University (No. 2005011).

\section{References}

1. Muller, O.; Gourzoulidou, E.; Carpintero, M.; Karaguni, I.M.; Langerak, A.; Herrmann, C.; Moroy, T.; Waldmann, H. Identification of potent Ras signaling inhibitors by pathway-selective phenotype-based screening. Angew. Chem. Int. Ed. 2004, 43, 450-454.

2. Barbera, J.; Raitin, O.A.; Ros, M.B.; Torroba, T. Breaking the mold of discotic liquid crystals. Angew. Chem. Int. Ed. 1998, 37, 296-299.

3. Austin, R.N.; Clark, T.J.; Dickson, T.E.; Killian, C.M.; Nile, T.A.; Schabacker, D.J.; McPhail A.T. Synthesis and properties of novel substituted 4,5,6,7-tetrahydroindenes and selected metal complexes. J. Organomet. Chem. 1995, 491, 11-18.

4. Alt, H.G.; Koppl A. Effect of the nature of metallocene complexes of Group IV metals on their performance in catalytic ethylene and propylene polymerization. Chem. Rev. 2000, 100, 1205-1221.

5. Thomas, E.J.; Rausch, M.D.; Chien, J.C.W. Synthesis of novel tetrahydrofluorenyl-containing group IV metallocenes for the Ziegler-Natta type polymerization of $\alpha$-olefins. Organometallics 2000, 19, 5744-5749.

6. Bertram, H.; Koch, O.; Woerner, P.; Surburg, H. Preparation and use of macrocyclic lactones as fragrances. EP 862911, 1998.

7. Griesbaum, K.; Frank, A.; McCullough, K.J. Syn- and anti-isomers of a O-methyloximesubstituted tricyclic ozonide. Eur. J. Org. Chem. 2006, 1978-1980.

8. Parham, W.E.; Rinehert, J.K. 1, 3-Bridged aromatic systems. II. New synthesis of metacyclophanes. J. Am. Chem. Soc. 1967, 89, 5668-5673.

9. Zakharkin, L.I.; Churiliva, I.M.; Pryanishnikov, A.P. Some transformations of 2benzylcyclodode- canones, prepared by alkylation of cyclododecanone with benzyl halides, under phase-transfer catalysis. Izv. Akad. Nauk Ser. Khim. 1993, 5, 905-907.

10. Miyamoto, M.; Harada, Y.; Tobisu, M.; Chatani, N. Rh(I)-Catalyzed Reaction of 2-(Chloromethyl) phenylboronic Acids and Alkynes Leading to Indenes. Org. Lett. 2008, 10, 2975-2978. 
11. Han, X.Y.; Wang, M.A.; Liang, X.M.; Wang, D.Q. Synthesis and conformation of cis-1,2disubstituted cyclododecene. Chin. J. Chem. 2004, 22, 563-567.

12. Wang, D.Q.; Yang, X.L.; Wang, M.A.; Liang, X.M.; You, T.P. Conformation of $\alpha$-monosubstituted cyclododecanones. Acta Chim. Sinica 2002, 60, 475-480.

13. Wang, M.A.; Zhang, N.; Lu, H.Z.; Wang, D.Q. Conformation of $\alpha, \alpha, \alpha^{\prime}$-trisubstituted cyclododecanone. Chin. J. Chem. 2007, 25, 1196-1201.

14. Wang, M.A.; Tu, G.Z.; Ma, Z.C.; Zhang, N.; Wang, D.Q. Synthesis and structural characteristic of two novel bicyclododecyl derivatives. Chin. J. Chem. 2006, 24, 205-209.

15. Wang, M.A.; Zhang, N.; Hou, X.T.; Wang, D.Q. Crystal and molecular structure of 2,3,5,6-bis(ortho-1,10-decylidene)dihydropyrazine. Chin. J. Struct. Chem. 2005, 24, 1254-1258.

16. Yang, X.L.; Wang, M.A.; Liang, X.M.; Wang, X.F.; You, T.B.; Wang, D.Q. Conformational effect on the keto-enol tautomerism of $\alpha$-carbonylcyclododecanones. Chin. J. Org. Chem. 2005, $25,1279-1282$.

17. Anet, F.A.L.; Rawdah T.N. The conformations of cis-cyclododecene. Evidence from dynamic NMR spectroscopy and iterative force-field calculations. Tetrahedron Lett. 1979, 1943-1946.

18. Tetsuya, A.; Bieri, J.H.; Manfred, H. Structures of Ring-Enlargement Products. Helv. Chim. Acta 1985, 68, 1033-1053.

19. Wang, X.L.; Xue, J.Y.; Hu, Z.; Tang, S.X.; Wang, R.J. The crystal structure and conformation of 15-phenylbicyclo[10.3.0]pentadec-1(12)-en-13-one. Chin. J. Chem. 1990, 8, 385-389.

20. Tang, J.W.; Liu, J.J.; Hu, Z.; Wang, X.L.; Yao, X.K.; Wang, J.R. Crystal structure of 15-methyl bicyclo[10.3.0]pentadec-1(12)-en-13-one and its stable molecular conformation. Chem. J. Chin. Univ. 1991, 12, 902-905.

21. Pawar, D.M.; Davis, K.L.; Brown, B.L.; Simith, S.V.; Noe, E.A. Conformational study of transcyclododecene by dynamic NMR spectroscopy and computational methods. J. Org. Chem. 1999, $64,4580-4585$.

22. Tsuji, J.; Yamada, T.; Shimizu, I. Syntheses of muscone and exaltone by three-carbon ring expansion. J. Org. Chem. 1980, 45, 5209-5212.

23. Li, K.; Ran, L.; Yu, Y.H.; Tang, Y. Synthesis and Characterization of Pentaerythritol-Derived Oligoglycol and Their Application to Catalytic Wittig-Type Reactions. J. Org. Chem. 2004, 69, 3986-3989.

24. Becke, A.D. A new mixing of Hartree-Fock and local density-functional theories. J. Chem. Phys. 1993, 98, 1372-1377.

25. Becke, A.D. Density-functional thermochemistry. III. The role of exact exchange. J. Chem. Phys. 1993, 98, 5648-5652.

26. Petersson, G.A.; Bennett, A.; Tensfeldt, T.G.; Al-Laham, M.A.; Shirley, W.A.; Mantzaris, J. A complete basis set model chemistry. I. The total energies of closed-shell atoms and hydrides of the first-row elements. J. Chem. Phys. 1988, 89, 2193-2218.

27. Frisch, M. J.; Trucks, G. W.; Schlegel, H. B.; Scuseria, G. E.; Robb, M. A. Gaussian 03, Revision B.03; Gaussian, Inc.: Pittsburgh, PA, USA, 2003.

Sample Availability: Samples of the compounds 2A-2E are available from the authors.

(C) 2010 by the authors; licensee Molecular Diversity Preservation International, Basel, Switzerland. This article is an open-access article distributed under the terms and conditions of the Creative Commons Attribution license (http://creativecommons.org/licenses/by/3.0/). 